\title{
Urban renovation through the implementation of a high-speed railway station
}

\author{
C. Mota $^{1} \&$ M. A. López ${ }^{2}$ \\ ${ }^{1}$ Department of Civil Engineering and Building Construction, \\ University of Castilla-La Mancha, Spain \\ ${ }^{2}$ Department of Mathematics, University of Castilla-La Mancha, Spain
}

\begin{abstract}
This paper contains certain considerations on a high-speed railway (HSR) station's area and its surroundings, as well as its reasons and effects thereof. The complexity and wide range of possible scenarios require a more specific context pertaining to medium-sized cities and a specific location of the station in those cities, i.e., the city centre.

The consulted bibliography includes many studies that focus on the analysis of the economic and territorial impacts of HSR, but just a few pay reference to what is going on in the station's surroundings, to the strategies and the results thereof. Nevertheless, the HSR experience in Europe has been the engine of many changes: for instance, in the early 90s, the Renaissance der Bahnhöfe phenomenon that emerged in Germany and took advantage of the new railway's service features in terms of speed, comfort, safety and advanced technical features for its repositioning, opened Europe to new activities, as well as to the presence of new means to transmit information, to the location of conference centres and to the opportunity to introduce or link several leisure activities. From the analysis based on the fieldwork carried out in certain stations in Germany, as well as from the study of their accessibility level, German cases are compared to other examples in Europe, especially to examples in a country in which HSR was implemented at the same time - Spain.

It can be concluded that evidently there are material differences in the ways to approach the revitalisation of stations and the urban surroundings thereof in order to take advantage of the building's renovation project and the
\end{abstract}


reorganisation of the railway environment as an important engine of urban renovation.

Keywords: high speed rail impacts, station area development, transit oriented design, urban design, urban regeneration, station area regeneration, high-speed rail (HSR) station.

\section{Introduction}

Thanks to decades of experience in the implementation of high-speed rail that have resulted in expertise, a position within the framework of the cities served can be adopted. On the contrary, critics underline the (selective) boosting of the transport system, the effects of polarisation, the comparative abandonment of regional railways or the oversizing of the HSR station area and the surrounding developments thereof. The effects are thus highly heterogeneous and sometimes they do not only depend on development and planning activities, but also on traditional models in the context of planning and mobility of each country's reality.

This is precisely the strategic point of the subject of this paper, through an approach to four cases in Europe: Fulda and Ulm in Germany and Toledo and Lerida in Spain.

\section{The high-speed railway station: a link between the network and the city}

Despite the fact that new transport systems are developed with a unimodal logic, in sight of the attempt to prioritise its competition compared to other transport modes, high-speed rail's degree of territorial consumption is as high as that of other controlled access infrastructures, which strengthens the centrality of those locations served - separated by big distances as per the infrastructure's own definition - but does not imply any advantages whatsoever. Under this circumstance, known as the "tunnel effect" [1-3], many scholars, [4-6] have historically found threat in a source of territorial unbalance that polarises space and establishes hierarchies within the cities system, and this has become a matter of concern even during the first year of this mode's implementation in Europe, as shown in the European Spatial Development Perspective (ESDP), which identifies the risks and warns of the importance of planning and coordination with other networks:

"Spatial development policy should work towards having high-quality transport infrastructure supplemented by secondary networks to bring about their positive effects in the regions" [7].

This way, through the existence and coordination of secondary, the network's polarising effects are not only mitigated but their capacity makes the convergence of greater volumes of traffic to the largest networks possible, which 
brings about benefits through their profitability and in time leads to a costbenefit compensation resulting in the service's improvement by means of benefits, destinations and schedules (De Rus et al. [8]).

Due to the foregoing discussion and despite the fact that a traditional perspective would implicitly assign a crucial role to the technological innovation applied to the revolutionary means of transport as a driver of development, with the danger of accepting this technological determinism as well as perceiving spatial and territorial developments as a simple reaction against the technological conditions and the potentials thereof (Luhmann [9]), the planning process is essential to turn associated risks thereto into opportunities. In this context, the high-speed railway station and its surroundings have different functions within the city they serve and take on a relevant position since they are a link between the networks(s): spaces with a high accessibility potential, new exhibition pieces where functions, activities and facilities are amalgamated, their regeneration being the flagship of urban planning in many cities served by HSR.

\section{Methodology}

Firstly, medium-sized cities with the station located in the city centre have been chosen within a wide range of possibilities when choosing the case study, since the integration of high-speed rail is more measurable in these kind of cities, (Burckhart [10]) - where the implementation of high-speed rail has a dramatic impact on accessibility $[11,12]$ - than in bigger ones that already have access to a previously implemented intermodality, leading to shared effects. In addition, countries where high-speed rail has been implemented for more than twenty years have been chosen; these cities are located in countries where there is not only a historical urban planning tradition administratively implemented in the field of physical planning but also with a historical spatial tradition acting as a link between economic and social planning.

In this light, the case studies that have been chosen are Ulm and Fulda in Germany and Lerida and Toledo in Spain; despite the fact that HSR was commissioned at a similar time - 1991 in Germany, 1992 in Spain - enabling a comparative framework, the differences found in terms of public transport policies and mobility tradition will show significant differences in the results. A prior consideration of them would be appropriate.

\subsection{Features inherent to each country regarding mobility and railway}

The conventional railway network, developed since 1825 , has a very uneven presence in European countries (Figure 1). In Germany, it is $43,800 \mathrm{~km}$ in length; in France, $31,939 \mathrm{~km}$; far from Spain, whose conventional railway network has only $14,743 \mathrm{~km}$ and a gauge of rails that is incompatible with the rest of Europe. If we compare these figures with those regarding to high-speed rail nowadays, the different application policies of the new mode can be found. 


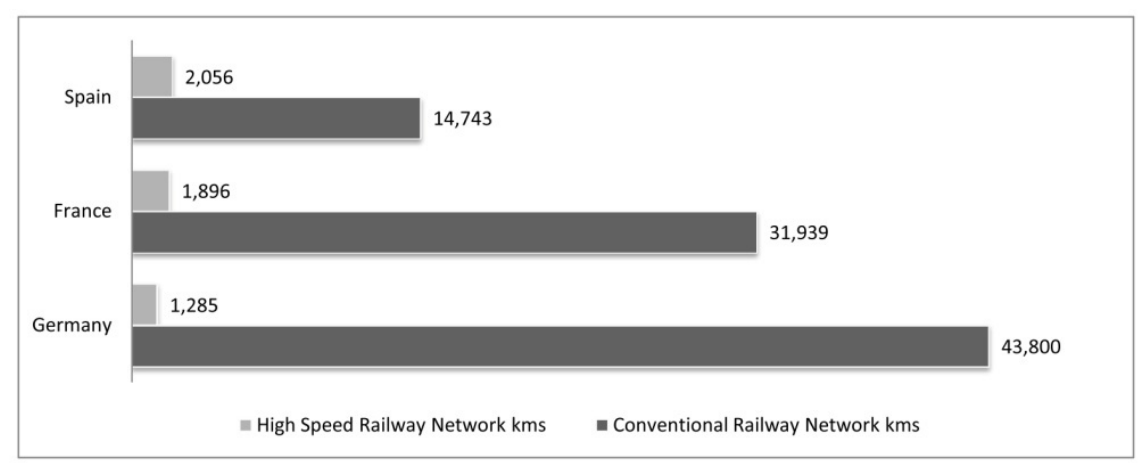

Figure 1: Length of the conventional and high-speed railway networks in service and planned. Source: Prepared by the author based on data from UIC 2010.

In addition, as pointed out by Burckhart [10], there are significant differences in the demand for railway services in Europe in a scenario prior to the current economic crisis. Germany, with $1,309 \mathrm{~km} / \mathrm{year}$ and Spain, with only 576 $\mathrm{km} /$ year. Regarding high-speed rail, Germans travel an average of $400 \mathrm{~km}$ in high-speed train every year, whereas Spanish only travel $50 \mathrm{~km} / \mathrm{year}$, which shows the poor popularity of Spanish high-speed rail network despite recent investments and differences in terms of railway mobility in the different networks. On the other hand, Germany is densely populated and has a tradition in terms of public transport use, which implies good accessibility in the vast majority of cities, whatever their size [13], and is far superior to the Spanish one.

In order to check against the different transformations that have taken place in each case upon the implementation of HSR, this paper focuses on two aspects:

- The planning processes of the station and its surroundings, regarding the level of accessibility by applying the "town planning" function. The "town planning" function $[14,15]$ was created to calculate the different static and dynamic indexes used to study networks through the graph theory by applying the Floyd Algorithm.

- The renovation or replacement of the building hosting high-speed rail.

\section{The German case}

In the German case, infrastructure investments in the node have traditionally received a particular interest, conceiving it as a link between city in mobility (tramway, metro, cycle paths and bus station - in the surroundings - normally converge) and functions, attaching great importance to the urban development that feeds back into its performance (Wulfhorst et al. [16]). Most German cities have a street at the railway station - Bahnhofsstraße - that is the most important link between the city centre and the railway station and becomes a counterpoint of the original mall (Schivelbusch [17]); as pointed out by Bodenschatz [18], this 
way it contributes to stimulating administrative activities and services. In the early 90s, a phenomenon commonly called Renaissance der Bahnhöfe (Köhler [19]) appears, precisely together with the implementation of high-speed rail. This phenomenon claims that the station must be the core of urban life again, as an attraction for showing the city to visitors and as a driving force for new passengers that contributes to sustainable urban development. In the $90 \mathrm{~s}$, the railway company crystallised these objectives through advertising examples that underlined that "Staying in the railway station must not be seen just as something necessary but as an opportunity to feel something" and in half of the 6,500 stations in Germany, the station's rebirth was seen as a revitalisation of stations and their urban surroundings simultaneously with a search for the sector's liberalisation, aiming at taking advantage of the building renovation project and the rearrangement of the railway environment as an important driver of urban remodelling. The Deutsche Bahn, by means of "Die Marke Bahnhof" and "Bahnhof der Zukunft" [20] performed renovation and modernisation works through the service extension to new offers related to the trip, such as the "travel centre", which studied the trip "from door to door" and extended transfers by train to destinations were linked and established new retail sale services, such as post offices, premises aimed at catering and food services, boutiques and even chemists. All of this policy was also accompanied by a travelling exhibition called "The stations' rebirth. The city in the $21^{\text {st }}$ century".

\subsection{Fulda}

Fulda's connection to the German high-speed network in 1992 contributed to its positioning as an important transport node within the German railway network that serves approximately 20,000 passengers every day. It is a class 2 Deutsche Bahn node that amalgamates an Intercity-Express stop, interurban and regional services. The original station was inaugurated as part of the Frankfurt-Bebra line in 1866; it was destroyed during World War II and rebuilt thereafter. The strategies developed in the city centre with the implementation of high-speed rail are especially interesting due to the policy of coordination with other transport networks (urban, regional and national) and to the role played by the station in its surroundings. The station, which serves a population exceeding Fulda's population, is used as a spot that links and coordinates the different transport modes. This way, the station becomes the fourth out of 249 most accessible vertex of the entire local network, according to the aforesaid "town planning" function.

In the mid-80s, the implementation of HSR was finally approved and the city started to get ready for the planning of the station and its surroundings. The first action performed was the transformation to reduce traffic volume by promoting the use of taxi and urban bus. This way, the adjacent bus station was built between 1989 and 1991. The total renovation of the station area was carried out, the surroundings were pedestrianised and the first floor was raised, opening accesses for car traffic (Figure 2). The entire traffic system of the city was modified and in 1992 all the historic quarter was closed to vehicles. Despite the 
fact that the city has a high heterogeneity of uses and administrative uses inherent to its hierarchy, residential, industrial use, etc., the number of houses in the station surroundings increased and commercial uses were promoted.
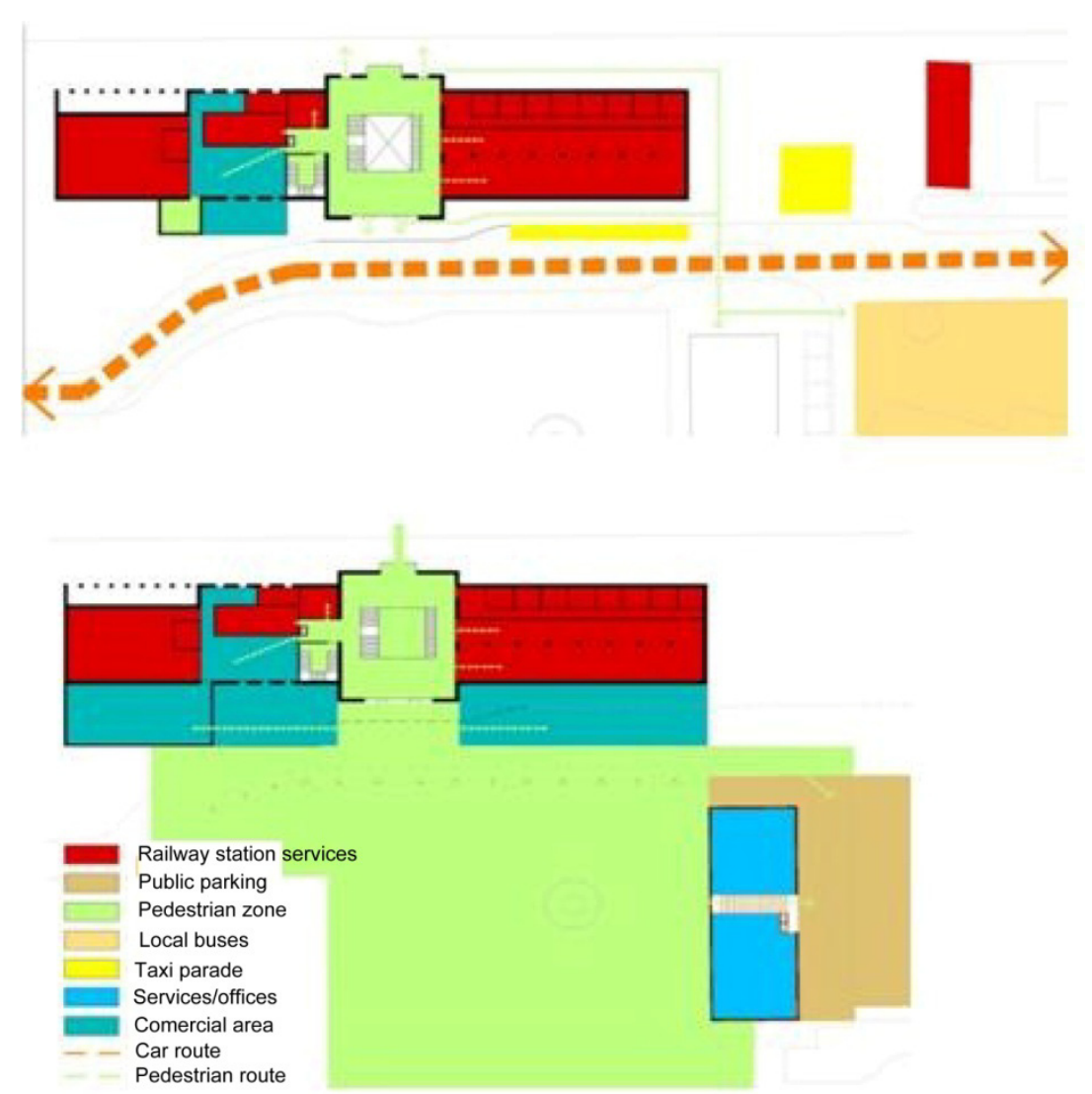

Figure 2: Station working schemes. First floor. Source: Prepared by the author.

\subsection{Ulm}

The Ulm case falls within the "Stuttgart 21" project. Ulm's central station, with an average of 40,000 users everyday and built in 1954, was already a maximum centrality spot - the most accessible spot out of 188 of the local network according to the aforesaid function-within the city and region before high-speed rail was implemented. In order to establish a perfect link for all the transport modes, the bases for a public tendering process were set to present a project for the station and its urban surroundings. The project included the station's general layout, with $2000 \mathrm{~m}^{2}$ for railway functions, $5000 \mathrm{~m}^{2}$ for retail sale and $2000 \mathrm{~m}^{2}$ of service areas. The general public was given the opportunity 
to participate in the tendering process through different local actions. The actions started to be developed on $1^{\text {st }}$ October 2004 and are ongoing at present; the estimated total cost amounts to 160 million euros and have a priority objective: a new positive definition of life in the city. The motto used for the NU21 project should be underlined, "Leben in der Stadt. Neu Definiert" (Living in the city. A new definition) by breaking the traditional railway barrier by relocating the tracks at a lower level and partially burying it.

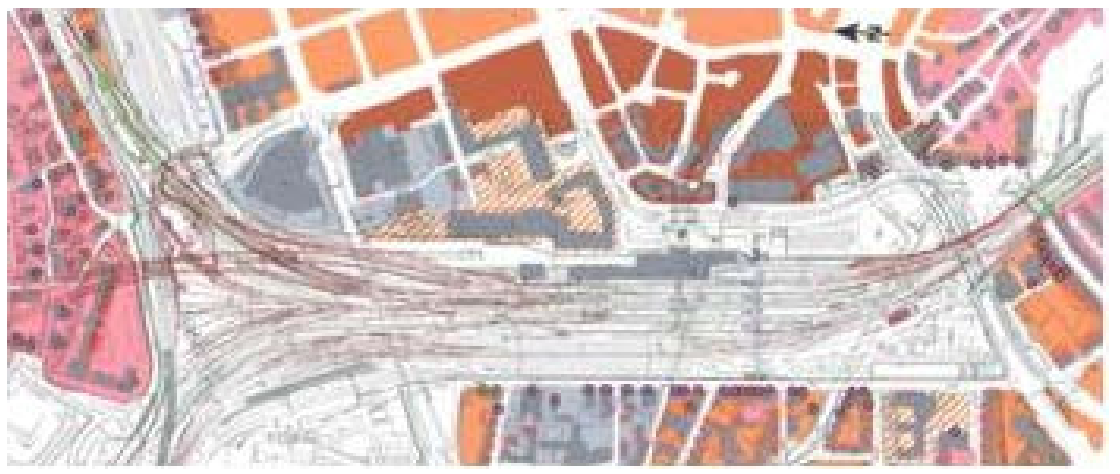

Figure 3: Städtebau Ramhmenplan, 2012. Ulm-Neu Ulm's Master Remodelling Plan. Source: Neu Ulm City Council.

This modification became part of the Städtebau Rahmenplan (Local Master Remodelling Plan), (Figure 3), approved on 2012: north from the street that covers the tracks are located those blocks dedicated to trade in order to invigorate the area, as well as the residential blocks with commercial premises.

\section{The Spanish case}

The Spanish case has big differences compared to the German model regarding not only the implementation of railway transport but also the mobility culture and many high-speed railway stations, especially those of small-sized cities, are located in the city outskirts. Nevertheless, these cases chosen do opt for the renovation of the existing station to implement the mode.

\subsection{Toledo}

The high-speed line with stop in Toledo, in service since 2005, is conceived as an independent line of the Madrid-Seville line, inaugurated in 1992.

When the high-speed line was implemented, the General Urban Planning Plan of 1986 was in force. Another document, the Local Planning Plan of 2007 is currently in force, although it is has been suspended by the High Court of Justice (Figure 4). While the General Plan of 1986 was in force, amendment no. 19 was introduced in order to arrange the land plots in the station surroundings before 
the implementation of high-speed rail but it was not executed. In the suspended plan, the analysis of the area crystallises in the action unit (UA27) that intends to complete the residential fabric around the station, guaranteeing its connectivity. It does not achieve this objective at present, since the station is the $73^{\text {rd }}$ most accessible spot within the local transport network.

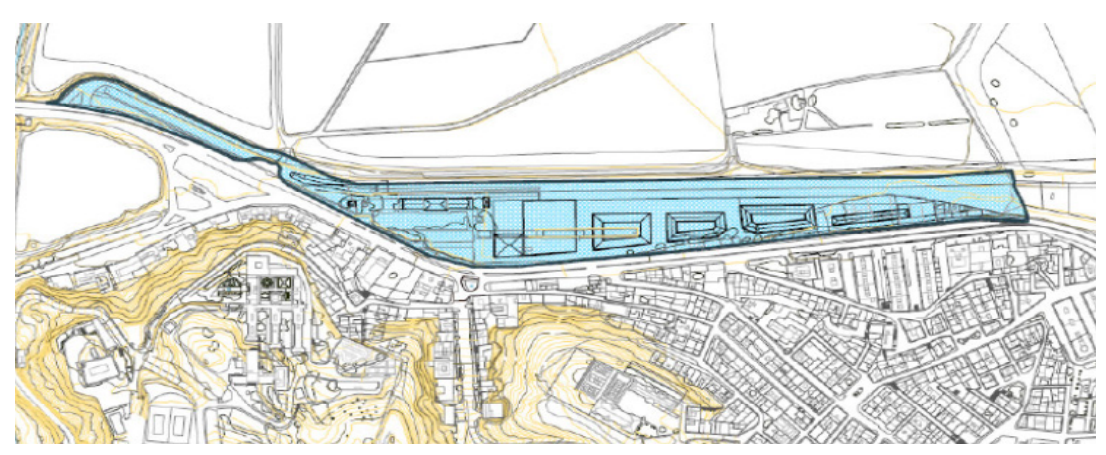

Figure 4: Modification proposal for the station surroundings. Source: Local Planning Plan of Toledo, 2007.

The station's renovated $19^{\text {th }}$ century building, which is small and only has ticket desk, a cafeteria and a waiting area, has the same features today: it is an industrial area, mainly with workshops and garages, surrounded by land plots that are not used at present but recently classified as developable.

\subsection{Lerida}

The final implementation project of high-speed rail in Lerida was approved in 1997, guaranteeing the connection between Figueres (Spain) and Perpignan (France) through a tunnel executed across the Pyrenees that is in service at present.

In the mid-90s, while the study for the optimal implementation of the railway service was being performed, the planning document was a general plan in force since 1979. The plan being outdated and due to the substantial modifications in the context conditions, the Plan Office was created in 1994. This way and upon rendering the municipal services, in 2003 the Regional Department of Spatial Policies of Catalonia approved the new General Plan (Figure 5), which incorporated the implementation of the new transport mode as one of the major strategies within the context of the urban project and intended to improve the urban environment defined in general plan PE3, aiming at crystallising the demands for improvements in the station area through a specific plan to that end; it was finally approved in December 2008. The strategic objectives sought are giving continuity to the city's neighbourhoods, improving the transport intermodality conditions and are rearranging building construction according to the new urban conditions. 
The station's building, built in 1929, was remodelled by creating a series of side covers attached thereto that cover the platforms and create a second side access. As in most stations of its kind in Spain, the services offered are a cafeteria, bookstore, car rental and ticket desks.

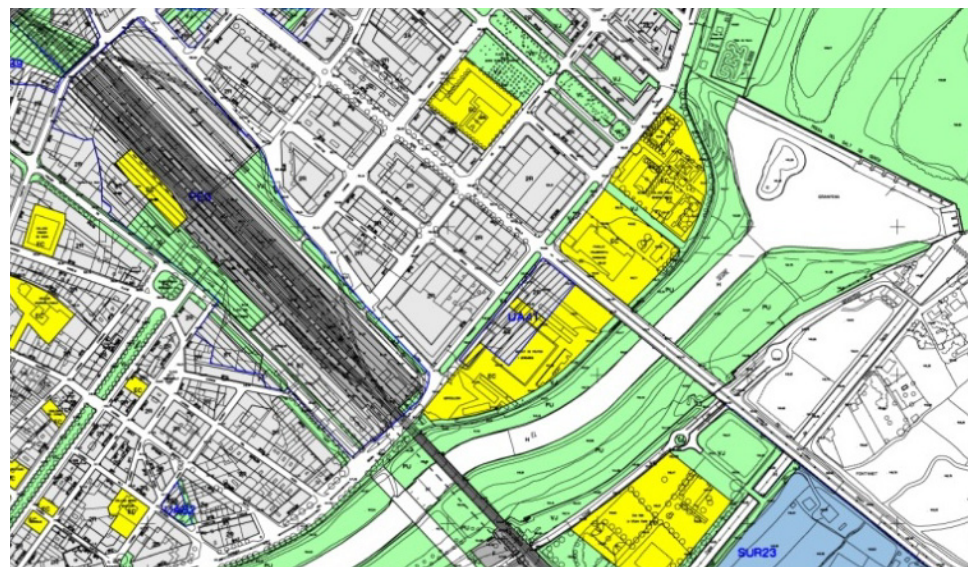

Figure 5: Urban Development Plan. Lerida City Council, 2003. Source: Lerida City Council.

\section{Conclusions}

The preparation of roads and walkways plans (Verkehrplanen) is clearly a factor that affects the planning of the station surroundings in the German case and the competencies thereof cover the modification of sections of streets or squares, the broadening of sidewalks, etc. It also affects the planning of new infrastructures for all kind of vehicles (commuter trains, metro, tramway, cycle lanes, roads, etc.), the modification of roads within the city and the flow of both motor and non-motor traffic (bikes and pedestrians). Due to the differences compared to Spanish legislation, understanding the scope of the actions carried out by this tool is specially interesting, as well as understanding the need for making mobility become a common tool in the legal framework of spatial planning. In the Spanish cases, to a greater extent in Toledo than in Lerida, the scope of intermodality by connecting the high-speed railway station is poorer, which, combined with a lower population density, has a negative impact when taking advantage of the infrastructure, its amortisation and thus of the opportunities to refinance improvements for it.

Regarding the complexity of the station's building, despite the fact that in Spain there is an increasing number of examples with more diversified functions, the huge German tradition makes the station's building act as a powerful driver of urban revitalisation and as a link between the network and the city. 


\section{References}

[1] Zembri, P., El TGV, la red ferroviaria y el territorio en Francia. Ingeniería y Territorio, 70, pp. 12-21, 2005.

[2] Mannone, V. L'impact régional du TGV Sud-est. Doctoral thesis of Geography, Université de Provence, 1995.

[3] Fariña, J., Lamíquiz, F. \& Pozueta, J., Efectos territoriales de la implantación de infraestructuras de accesos controlados. Cuadernos de investigación urbanística, 29, 2000.

[4] Plassard, F., Le train à grande vitesse et le réseau des villes. Transports, 345, pp. 14-23, 1991.

[5] Troin, J.F., Rail et aménagement du territoire. Des héritages aux nouveaux défis, Edisud, 1995.

[6] Menerault, P., Processus de territorialisation des réseaux: analyse de la grande vitesse ferroviaire á l'échelle régionale. Networks and Communication Studies NETCOM, 12 (1, 2, 3), pp. 161-184, 1998.

[7] European Commission: Pour le developpement d'un reseau européen de trains à grande vitesse. Commission of the European Communities, Brussels, 1990.

[8] De Rus, G. \& Nash, C., En qué circunstancias está justificado invertir en líneas de alta velocidad ferroviaria? Fundación BBVA, documentos de trabajo, 2009.

[9] Luhmann, N., Politische Planung. Aufsätze zur Soziologie von Politik und Verwaltung. Opladen: Westdeutscher Verlag, 1971.

[10] Burckhart, K., Análisis comparativo y evaluación cuantitativa de la intermodalidad del tren de alta velocidad. Una perspectiva europea de la interconexión e integración en estaciones ferroviarias de ciudades intermedias. Doctoral thesis, Universitat de Lleida, 2007.

[11] Wolfram, S., Planning concepts for the Integration of the High Speed Train into Metropolitan Regions- a comparative study four European cases. Doctoral thesis, Universität Stuttgart, 2003.

[12] Varlet, J., Dynamique des interconnexions des réseaux de transports rapides en Europe: devenir et diffucion sapatiale d'un concept géographique. Flux, 41, 2000.

[13] Projekt des Forschungsprogramms, Allgemeine Ressortforschung des Bundesministeriums für Verkehr. Bau und Stadtentwicklung (BMVBS) und des Bundesamtes für Bauwesen und Raumordnung (BBR), Bonn, 2009.

[14] Mota, C., Planning of the implementation of high-speed rail. A comparative study on the planning policies from the analysis of the territorial implications thereof. Doctoral thesis, Universidad de CastillaLa Mancha, 2013.

[15] López, M.A., Martínez, R. \& Mota, C., Analysis of transport networks in the urban environment in order to plan the integration of high-speed rail. Applied Mathematics \& Information Sciences, to appear, 2014. 
[16] Wulfhorst, G., Berckmann, K., Huneche, M. \& Heinze, M., Rauemnutzung und Mobilitätverhalten: Wechelwirkungen zwischen Stadtwicklung, Lebensstil und Verkehrsnachfrage. Gestaltungopinionen für eine zukunftsfähige Mobilität. Gelsenkirchen. Secretariat f'r Zukunftsforschung, 2000.

[17] Schivelbusch, W., Geschichte der Eisenbahnreise, Carl Hanser: München und Wien, 1977.

[18] Bodenschatz, H., Moderne Infrastruktur und die Produktion städtischer Lage. Das Beispiel des deutschen Eisenbahnbaus bis 1875. In: Fehl, G.; Rodríguez-Lores, J. (Hrsg.), Stadterweiterungen 1800-1875, Hamburg, 1983.

[19] Köhler, S., Entwicklung der Verkehrsinfrastruktur in einer mobilen Gesellschaft. Dargestellt am verkehrsfunktionalen und städtebaulichen Bedeutungswandel der Bahnhöfe, Infrastruktur in einer mobile Gesellschaft, Hannover, pp. 68-91, 2007.

[20] Die Marke Bahnhof; Bahnhof der Zukunft. Deutsche Bahn AG, Geschäftsbereich Personenbahnhöfe, 1996. 